\title{
Análise da operacionalização da política de aquisição de alimentos da agricultura familiar por parte dos municípios: o caso do PNAE em três microrregióes do Oeste Catarinense ${ }^{1}$
}

\author{
Darlan Christiano Kroth \\ Universidade Federal da Fronteira Sul/Campus Chapecó - Chapecó - Santa \\ Catarina - Brasil \\ Valdecir José Zonin \\ Universidade Federal da Fronteira Sul/ Campus - Erechim - Rio Grande do Sul - \\ Brasil

\section{Tomé Coletti} \\ Universidade Federal da Fronteira Sul/Campus Chapecó - Chapecó - Santa \\ Catarina-Brasil

\section{Willian Simões} \\ Universidade Federal da Fronteira Sul/Campus Chapecó - Chapecó - Santa \\ Catarina - Brasil

\section{Eduardo Von Dentz} \\ Universidade Federal de Santa Catarina - Florianópolis - Santa Catarina - Brasil
}

\section{Resumo}

O presente estudo tem como objetivo avaliar a governança por parte das prefeituras municipais do Programa Nacional de Alimentação Escolar (PNAE), conforme a Lei $n$. 11.947/2009, que prevê a aquisição de alimentos oriundos de agricultores familiares no valor mínimo de 30\% dos recursos do Fundo Nacional de Desenvolvimento da Educação (FNDE). 0 trabalho lançou mão de estudo de caso em três microrregiões do Oeste de Santa Catarina (Chapecó, Concórdia e Xanxerê), considerando uma amostra constituída de 31 municípios. Os principais resultados demonstraram que o PNAE vem se apresentando eficaz, atingindo seus principais objetivos, em termos de fortalecimento da agricultura familiar, de proporcionar melhor qualidade nutricional para os alunos e de promover o desenvolvimento local/regional. Por outro lado, esses resultados poderiam ser maiores (ampliando a eficiência da política),

${ }_{1}^{1}$ Pesquisa realizada em âmbito do Projeto de Fortalecimento da Juventude Rural na Região Oeste de Santa Catarina, aprovado pelo CNPq, segundo a Chamada MCTI/MDA-INCRA/CNPq N 19/2014. 
caso a governança do Programa por parte das prefeituras municipais fosse mais robusta. A pesquisa verificou, ainda, que apenas quatro prefeituras (13\% de nossa amostra) realizam uma gestão considerada adequada do Programa, no sentido de desenvolver ações de organização da produção, auxílio logístico e assessoria técnica aos agricultores.

Palavras-chave: PNAE. Agricultura familiar. Mercados institucionais. Oeste de Santa Catarina.

\title{
Analysis of the policy of food acquisition of family agriculture by the municipalities: the case of PNAE in three microregions of the West of Santa Catarina
}

\begin{abstract}
This study aimed to evaluate the governance by the municipalities of the National School Feeding Programme (PNAE), according to Law n. 11.947/2009 which provides for the purchase of food from family farmers at a minimum value of $30 \%$ of the resources of the National Fund for Education Development. The work launched case study hand in three micro-regions of the West of Santa Catarina (Chapecó, Concordia and Xanxerê) considering a sample of 31 municipalities. The main results showed that the PNAE has been performing effective, achieving its main objectives in terms of strengthening family agriculture, to provide better nutritional quality for students as well as a promoter the local and regional development. On the other hand, these results could be higher (increasing the efficiency of the policy) if the governance of program by the municipalities were more robust. The survey found that only four municipalities ( $13 \%$ of our sample) perform a program management considered appropriate in terms of developing organizational actions of production, logistical support and technical advice to farmers.

Key-words: PNAE. Family farmers. Institutional markets. West region of Santa Catarina.

\section{Análisis de la operacionalización de la política de adquisición de alimentos de la agricultura familiar por parte de los municipios: el caso del PNAE en tres microrregiones del Oeste Catarinense}

\section{Resumen}

El presente estudio tiene como objetivo evaluar la gobernanza por parte de las alcaldías municipales del Programa Nacional de Alimentación Escolar (PNAE), conforme a la Ley n. 11.947 / 2009, que prevé la adquisición de alimentos provenientes de agricultores familiares por un mínimo del 30\% de los recursos del Fondo Nacional de Desarrollo de la Educación (FNDE). El trabajo emprendió un estudio de caso en tres microrregiones del Oeste de Santa Catarina (Chapecó, Concordia y Xanxerê), considerando una muestra constituida de 31 municipios. Los principales resultados demostraron que el PNAE se está presentando eficaz, alcanzando sus principales objetivos, en términos de fortalecimiento de la agricultura familiar, proporcionar mejor calidad nutricional para los alumnos y promover el desarrollo local / regional. Por otro lado, esos resultados podrían ser mayores (ampliando la eficiencia de la política), si la gobernanza del Programa por parte de las alcaldías municipales fuese más robusta. La investigación verificó, además, que sólo cuatro prefecturas (13\% de nuestra muestra) realizan una gestión considerada adecuada del Programa, en el sentido de desarrollar acciones de organización de la producción, auxilio logístico y asesoría técnica a los agricultores.

Palabras clave: PNAE. Agricultura familiar. Mercados institucionales. Región Oeste de Santa Catarina.

1 Introdução 
O Brasil vem ampliando e aprimorando o rol de políticas públicas para o Desenvolvimento Rural (DR) a partir de 2003. Dentre essas políticas, enquadram-se a construção de mercados institucionais - política de compras governamentais direcionadas à agricultura familiar -, como o Programa de Aquisição de Alimentos (PAA) e o Programa Nacional de Alimentação Escolar (PNAE). Uma das inovações dessas políticas é seu caráter sistêmico, ou seja, entrelaçam-se com outras áreas, como educação, saúde e assistência social, e ampliam seus efeitos sobre a sociedade. Nesse sentido, o PAA está articulado à política de combate à fome e o PNAE à política educacional, ainda que ambos se articulem com a política de segurança alimentar e nutricional.

Para Schneider (2010) e Grisa e Schneider (2015), a construção de mercados institucionais no país é o desdobramento de uma trajetória de políticas públicas que ganharam impulso na década de 1990, por meio da mobilização social e de estudos em DR, que foram se materializando ao longo dos anos ${ }^{2}$. Nesse sentido, a promulgação da Lei n. 11.947/2009, que exige a compra de alimentos da Agricultura Familiar (AF) de, no mínimo, 30\% dos recursos advindos do Fundo Nacional de Desenvolvimento da Educação (FNDE) pode ser considerada como um resultado desse movimento.

$O$ mercado institucional do PNAE tem como grande mérito, além da priorização da produção de alimentos da Agricultura Familiar (AF), incorporar ao tema da alimentação escolar a preocupação com a Segurança Alimentar e Nutricional (SAN). Assim, o novo formato do PNAE permite atingir vários resultados, como hábitos de alimentação saudável e, por conta disso, melhoria da saúde e do desempenho escolar dos alunos, o fortalecimento da AF, a maior cooperação entre os agricultores e o desenvolvimento regional.

Uma característica importante da operacionalização do PNAE é o papel dado aos entes federados, com destaque para os municípios na governança destas políticas 3 . Conforme dados do FNDE (2018), em 2011, apenas 26,7\% dos municípios brasileiros atingiram o mínimo de $30 \%$ de aquisição da $\mathrm{AF}$, número ampliado para 42,1\%, em 2016. Em Santa Catarina, essa realidade está um pouco melhor, 58\%, em 2011, e 75,8\%, em 20164. Verifica-se, dessa forma, que ainda há um grande espaço para avançar no PNAE, e esse avanço passa, principalmente, pela superação de alguns gargalos na gestão do Programa (TRICHES, 2015).

Nesse contexto, o presente estudo tem como principal objetivo analisar a operacionalização dessa política pelos municípios de três microrregiões do Oeste de Santa Catarina, possibilitando responder a questões referentes à demanda de alimentos da AF, à gestão do Programa e aos instrumentos para aprimorar tal política. Para dar conta desse objetivo, optou-se pela realização de estudo de caso, considerando uma amostra de 31 municípios. As entrevistas foram realizadas por meio de cinco fóruns (denominados de oficinas regionais), nos quais, além das

\footnotetext{
${ }^{2} \mathrm{~A}$ construção de mercados institucionais e de políticas para seu desenvolvimento, também vem ganhando destaque na literatura internacional, conforme Heibinck et al. (2015).

${ }^{3}$ A governança (ou gestão) da política pública segue os preceitos apresentados por Secchi (2013), em que há uma participação efetiva do gestor público (e de seu quadro técnico) em todas as fases da política, iniciando pela formulação, passando pela execução até sua avaliação e socialização dos resultados com a comunidade.

${ }^{4}$ Conforme observação do FNDE, esses dados são preliminares.
} 
entrevistas individuais, pode-se fazer uma socialização das experiências e debate acerca do Programa.

Destaca-se que a região Oeste de Santa Catarina, objeto do estudo, é caracterizada pela presença de grande parcela de agricultores familiares, sendo considerada um modelo desse tipo de agricultura para o país (MIOR, 2005). Além disso, a região enfrentou até o início dos anos 2000, um processo intenso de modernização agrícola, que resultou na exclusão de grande parte dos pequenos produtores menos capitalizados, gerando um forte processo de êxodo rural, somado a impactos negativos sobre o meio ambiente (TESTA et al, 1996). Atualmente, as propriedades rurais remanescentes observam a saída de jovens, que acarreta problemas na sucessão familiar dessas propriedades e na manutenção do modelo produtivo da AF.

Nesse prisma, o presente estudo pretende contribuir com a literatura, no intuito de avaliar os efeitos do PNAE, através da Lei n. 11.947/2009, em uma região caracterizada por esse tipo de população e que apresenta necessidade de políticas de DR. Além disso, a metodologia adotada permite avançar - se comparada a outros trabalhos na área - na medida em que lança o olhar sobre a governança do Programa nos municípios e considera uma amostra significativa.

O trabalho está estruturado em seções, divididas a fim de organizar e facilitar a compreensão do texto em sua unidade semântica. Assim a seção dois discute o que são mercados institucionais, como a construção deste tipo de mercado se insere no processo de DR e como as políticas públicas podem auxiliar no seu fortalecimento e ampliação. Na sequência, traz uma síntese da evolução do PNAE, com destaque para trabalhos que avaliaram o desempenho do Programa. A seção três apresenta a metodologia, e a quatro expõe e analisa os resultados. À guisa de fechamento, a seção cinco, expõe as principais conclusões do estudo.

\section{Mercados institucionais}

O estudo dos mercados institucionais 5 tem sua origem na literatura da Nova Economia Institucional (NEI), que contempla a base conceitual dos mercados institucionais, como as instituições per se e os custos de transação. No que concerne as instituições, Hodgson (2004) define-as como sistemas duráveis de regras sociais estabelecidas e incorporadas que estruturam as interações sociais, logo, as relações econômicas na sociedade são reguladas por instituições. Conforme Bueno (2004), a NEI considera que as instituições são criadas na sociedade, a partir de complexos processos de negociação, visando reduzir os custos envolvidos em um empreendimento conjunto, realizado entre agentes/atores que detêm racionalidade limitada e são propensos a agir de forma oportunista6 ${ }^{6}$.

Neste sentido, os custos de transação referem-se aos riscos contratuais existentes em uma transação específica, e, para reduzi-los, surgem diferentes formas de contratos. Tais custos assumem basicamente quatro formas: i) custos para adquirir e processar informações; ii) custos voltados a organizar a produção,

\footnotetext{
${ }^{5}$ Os mercados institucionais também são chamados de nested markets (mercados aninhados, em uma tradução livre). Utiliza-se, no presente texto, os termos "mercados institucionais" ou "novos mercados" de forma intercambiada.

${ }^{6}$ Os principais expoentes da NEl são Douglas North, Ronald Coase e Oliver Willianson.
} 
incorridos pelo comportamento ineficiente das partes contratantes; iii) custos de monitoramento do esforço das partes envolvidas em uma negociação; e iv) custos legais associados ao gerenciamento de cláusulas contratuais.

Partindo da base da NEl, Heibinck et al (2015), conceitua mercados institucionais como estruturas de comércio e distribuição de produtos agrícolas, criados ao redor de recursos disponíveis em uma região, estruturados sob regras sociais e governados pela estruturação de instituições criadas para tal. Embora apresentem formatação diversificada, têm como característica central a ação coletiva e a cooperação entre agricultores e demais entidades participantes (cooperativas, associações de produção, de consumo e agências ou órgãos de Governo).

Outra definição é dada por Ploeg (2015), para quem os novos mercados são segmentos de mercados maiores (já consolidados), como, por exemplo, o mercado global de commodities. As principais diferenças em relação aos mercados tradicionais referem-se a sua dinâmica, interrelações entre os atores, diferenciais de preço, formas de governança, mecanismos distributivo e principalmente, impacto. $\mathrm{O}$ autor argumenta, ainda, que os mercados tradicionais desempenham duas funções importantes para os mercados institucionais: impelem a criação desses novos mercados e garantem sua perenidade em virtude da existência de brechas infraestruturais?.

Ao propor uma base teórica para análise dos mercados institucionais, Ploeg (2015) apresenta quatro elementos constituintes desses mercados, os quais devem atuar conjuntamente, a saber: multifuncionalidade, diversificação, infraestrutura sociomaterial e recursos comuns. A multifuncionalidade é o movimento que impele para a oferta de novos produtos e serviços, que devem ser diferentes daqueles que já estão colocados no mercado tradicional e que atendam a uma demanda reprimida da sociedade, como é o caso dos produtos de maior qualidade (coloniais e orgânicos) ${ }^{8}$.

É preciso considerar a ideia de que a diferenciação é a característica do produto que lhe confere maior valor agregado. Para Ploeg (2015), esse elemento é fundamental para que os produtos da AF possam competir com os produtos convencionais. Produtos convencionais (geralmente ligados a grandes empresas) são produzidos em grande escala, o que reduz seu custo e, portanto, permite que possam ser disponibilizados ao mercado a um menor preço. Em razão disso, o autor aponta que, caso a AF fosse direcionar seus novos produtos para mercados tradicionais, provavelmente não sobreviveria.

Importante destacar, ainda, que, para que diferenciação obtenha sucesso, é necessário que tenha consumidores diferenciados, com capacidade de distinguir e apreciar a diferenciação. A existência de tais consumidores pode gerar, inclusive,

\footnotetext{
7 As "brechas estruturais" podem ser analisadas em termos de oportunidades negociais, como, por exemplo, a entrada de produtos japoneses no mercado americano nos anos 1980. Um exemplo de "brecha estrutural" para o setor de alimentos seria a percepção de falta de qualidade na produção industrial, em virtude do processamento químico que os alimentos sofrem. Nesse caso, o buraco/brecha seria a oferta de produtos de qualidade, frescor e de origem local, criando um novo espaço a ser explorado dentro do mercado convencional.

${ }^{8}$ Para Ploeg (2015), a multifuncionalidade da agricultura se refere às novas modalidades de atividade agrícola (trabalho casual, turismo rural, proteção do meio ambiente, produtos orgânicos e coloniais) que surgiram nos últimos anos, aliada, muitas vezes, a formas convencionais, como resposta às dificuldades da globalização.
} 
feedbacks entre consumidores e agricultores, reforçando o impacto das redes sociais em direção ao desenvolvimento e aperfeiçoamento de produtos (processo conhecido como inovação via aprendizado pela interação - learning by interaction).

A infraestrutura sociomaterial se refere ao lócus do mercado propriamente dito (uma feira ou uma cooperativa de produtos da AF) e às formas de negociação nesse mercado (vendas de produtos em feiras, vendas direta ao consumidor ou vendas em mercearias) e pode incluir, também, uma marca para os produtos. A infraestrutura sociomaterial é, portanto, a ponte que liga os produtos diferenciados dos agricultores às brechas (oportunidades negociais). Nesses termos, os mercados institucionais são um exemplo dessa infraestrutura. Vale ressaltar que, a partir da consolidação da infraestrutura sociomaterial, um ciclo virtuoso pode iniciar, na medida em que novos produtos podem surgir como resultado da experiência e aprendizado (processo também conhecido como learning by doing).

O último elemento, os recursos comuns, refere-se à capacidade de gerar benefícios comuns aos atores envolvidos e, ao mesmo tempo, evitar que tais benefícios sejam afetados por comportamentos oportunistas. Também podem ser definidos como as formas de governança desse mercado e as redes (e relações) sociais criadas em seu entorno. Essas relações sociais conectam e permitem transações, comunicação e fluxo de informações se realizarem, ou seja, criam diferentes formas de interdependência e interação. Dessa maneira, os recursos comuns representam a confiança, a cooperação e a reciprocidade entre produtores, consumidores, entidades de apoio e governo.

Com arrimo nos conceitos propostos por Milone e Ventura (2015), pode-se classificar os mercados institucionais em três categorias: i) mercados completos: mercados para um novo bem (Ex.: proteção do meio ambiente); ii) mercados construídos através de segmentos de mercados já existentes, por meio da diferenciação de produtos (Ex.: produtos orgânicos e coloniais); e iii) mercados construídos mediante políticas públicas para promover o acesso de novos segmentos da população à produção de alimentos locais (Ex: PAA e PNAE).

Ainda segundo Milone e Ventura (2015), os mercados institucionais trazem em si elementos que favorecem a redução dos custos de transação, o que passa a ser uma de suas principais características competitivas em relação aos mercados tradicionais ${ }^{9}$. Nos mercados institucionais, essa redução de custos se dá pela forma como o mercado é construído (infraestrutura sociomaterial) e governado (recursos comuns). Nesse viés, a interação (feedbacks) entre consumidores e produtores substitui as pesquisas de mercado tradicionais, a divulgação dos produtos (propaganda) é realizada pela própria rede social criada, e o monitoramento contra atos oportunistas é realizado pelo sistema de governança. Além da redução dos custos, Milone e Ventura (2015) também consideram que processos inovadores podem surgir a partir dessa interação entre os atores e instituições criadas, em

\footnotetext{
9 Nos mercados tradicionais, há um elevado conjunto de regras e custos, que nem sempre são possíveis de serem absorvidos por pequenos e/ou novos empreendimentos. Portanto, mercados tradicionais buscam formas para reduzir esses custos, como é o caso do sistema de integração da agroindústria de carnes no Oeste Catarinense, a qual criou um sistema que define regras (ou contrato), como especificação da qualidade, quantidade e formas de pagamento, para reduzir os custos de transação.
} 
processos nos quais se aprende fazendo (learning by doing), pela interação (learning by interaction) e pela ampliação de know-how.

Compreender a configuração de um mercado institucional possibilita visualizar a relevância de alguns instrumentos de incentivo e de regulação (ou aparato institucional) para prover a consolidação desses mercados, como é o caso de políticas públicas específicas (PLOEG et al, 2015). Corroborando com essa visão, Heibinck et al (2015) avaliam, ainda, que o desenho dessas políticas públicas deve considerar os atores envolvidos no processo, como agricultores familiares, comerciantes, consumidores, movimentos sociais, entidades e Governo ${ }^{10}$.

\section{A construção de mercados institucionais como política pública para o DR}

O DR pode ser entendido, conforme Kageyama (2004), como um processo multifacetado que objetiva a melhoria das condições de vida das populações rurais (ou mais especificamente dos agricultores familiares), abrangendo desde a criação de novas formas de geração de renda, infraestrutura no campo, lazer, sustentabilidade ambiental, rede de seguridade social, políticas agrícola e agrária e sucessão familiar, até a preservação da cultura, conhecimentos, tradições da vida rural - em que pese sua inserção nos modos e meios de vida contemporâneos. Três elementos importantes estão presentes nessa definição. O primeiro é que o DR amplia as oportunidades de acesso às políticas públicas pelas populações rurais. $O$ segundo se refere ao fato de que esse tipo de desenvolvimento transborda seus efeitos para o local e regional, ou seja, seus benefícios não são absorvidos apenas pelo mundo rural, mas por toda a sociedade. Nesse sentido, o DR contribui para o desenvolvimento regional. O terceiro elemento significativo nessa relação é a presença do Estado como mediador e catalisador desses processos, por meio da realização de políticas públicas.

Segundo Navarro (2001), o conceito de DR se constrói a partir da própria concepção mais genérica de desenvolvimento (como desenvolvimento econômico e suas demais conotações: local, sustentável, regional), englobando, então, esses elementos. Outro aspecto importante na definição acerca do que é o DR, é que ele se modifica ao longo do tempo, na medida em que novas conjunturas/realidades emergem e impactam na vida das famílias rurais. Nesses termos, o autor também aponta para o fato que o DR, como proposto aqui, afasta-se de outras definições próximas, como desenvolvimento agrário e agrícola e, portanto, é muito mais amplo que essas duas concepções de desenvolvimento ${ }^{11}$.

Em sintonia com esse arcabouço teórico, Heibinck et al (2015) se debruçam na proposição de políticas públicas de DR. Na sua concepção, a elaboração de políticas deve considerar dois elementos basilares. O primeiro decorre de colocar as práticas de DR no estágio central da política, isto é, o DR não pode ser considerado uma metanarrativa que vai da política pública para a prática, tampouco é um domínio exclusivo

\footnotetext{
${ }^{10}$ Os instrumentos de política que podem ser utilizados para promover os novos mercados podem ser as compras institucionais, linhas de crédito para fomentar a infraestrutura sociomaterial, fomento de pesquisa e extensão em produtos da AF, regulação de mercado como legislação sanitária.

11 Segundo Navarro (2001, p. 86), o desenvolvimento agrícola estaria relacionado "...exclusivamente às condições da produção agrícola e/ou agropecuária, suas características, no sentido estritamente produtivo...”. Já o desenvolvimento agrário refere-se a “...interpretações acerca do 'mundo rural' em suas relações com a sociedade maior, em todas as suas dimensões...”.
} 
dos formuladores de política ou acadêmicos. Mais adequado, o DR é modelado por um múltiplo conjunto de práticas que são iniciados e desenvolvidos em resposta às falhas de mercado. Segundo os autores, política é uma prática, e quanto mais ela se entrelaça a outras práticas, maior é sua efetividade. Em resumo, a política não é o ponto inicial do DR, mas deve ser resultado da interação entre os atores. O segundo elemento consiste em direcionar o foco para o papel dos atores envolvidos, principalmente os agricultores familiares e suas organizações econômicas, sociais e políticas.

Nesta perspectiva, a constituição de mercados institucionais para produtos da agricultura familiar, vem sendo utilizado como instrumento de DR em experiências internacionais e nacionais (NIEDERLE et al, 2014). Os mercados institucionais, conforme já destacados na seção anterior, apresentam características - e são estruturados - de forma diferente das vigentes nos mercados convencionais, destacando-se uma nova forma de governança entre os diversos atores envolvidos.

Na mesma linha, segue o estudo de Chang (2009), ao avaliar políticas para a agricultura realizadas no passado em várias economias desenvolvidas, e, mais recentemente, em economias em desenvolvimento. $\mathrm{O}$ autor sugere, como uma das possíveis ações de políticas públicas para economias em desenvolvimento, o fortalecimento de mercados institucionais. Além disso, aponta a necessidade de providências como a ampliação dos canais de comercialização e o processamento de produtos, a modernização dos canais de comercialização e a produção de produtos de qualidade, destacando que tais iniciativas (e suporte) públicas (os) devem se coadunar com as experiências e proposições dos agricultores envolvidos.

No Brasil, os mercados institucionais foram sendo constituídos de forma independente pelos próprios agricultores e movimentos ligados a $\mathrm{AF}$, através de feiras livres e feiras de produtos coloniais e agroindustriais, com participação marginal do Estado (CONTERATATO et al, 2013). Conforme estudo de Niederle e Grisa (2008), estas iniciativas da AF, expõem o movimento de diversificação de atividades no seio da AF como resposta a superação de crises (e/ou choques externos) de natureza econômica, política e ambiental/ecológica que a AF enfrentou com maior vigor no início dos anos 1990, e da superação de sua condição passiva frente ao sistema agroalimentar convencional que os torna mais vulneráveis a estas crises. A diversificação se alicerça a partir da constituição e desenvolvimento de ativos (recursos) oriundos da própria AF, como capital social, capital humano e capital produzido ${ }^{12}$.

Para Silva e Silva (2011) a consolidação de mercados institucionais como política pública ocorre a partir da constituição de programas de compras governamentais, tendo como principal exemplo, o PAA em 2003, em âmbito do Programa Fome Zero. Neste sentido, os mercados institucionais como política pública no Brasil, surgem de um conjunto de elementos complementares que criam as condições adequadas para a elaboração da política pública, como a trajetória de experiência dos próprios agricultores, da reivindicação e mobilização dos movimentos sociais ligados a AF por melhorias no campo, do histórico de estudos em DR que permitem desenvolver instrumentos para formatar a política e, da conjuntura

${ }^{12}$ Capital produzido compreende a infraestrutura (estradas, energia, telecomunicações, pontes), recursos financeiros (dinheiro, crédito, poupança) e meios de produção (máquinas, equipamentos, implementos, barracões). 
política favorável, contando com um governo sensível a estes movimentos e preocupado com o DR, que acolheu e implementou tais propostas (SACCO DOS ANJOS; BECKER, 2014). Para Grisa e Schneider (2015) a constituição de mercados institucionais demarca a terceira geração de políticas para a $A F$, iniciada com o PRONAF nos anos 1990.

\section{A construção do mercado institucional para a AF a partir do PNAE}

O PNAE é um dos programas alimentares mais antigos do país, tendo iniciado no ano de 1955. Mas, em quase todo o período de existência, manteve-se como um programa de caráter assistencialista e centralizador, em que o órgão central do Governo planejava os cardápios e realizava as compras para todo o país, sem espaço para AF e sem vínculos com o desenvolvimento regional sustentável. Apenas em 1994, quando ocorre a descentralização dos recursos aos municípios, o Programa passa a ter uma característica mais próxima da realidade regional brasileira, oferecendo maior espaço para os municípios gerirem a alimentação escolar, como a compra dos alimentos, a elaboração dos cardápios e a criação do Conselho de Alimentação Escolar (CAE) (TRICHES, 2015).

Mas é a partir de 2003 que o PNAE passa a ser incorporado em uma política de DR, quando insere uma nova concepção de alimentação escolar, em termos de Segurança Alimentar e Nutricional (SAN). De acordo com Maluf (2007), essa concepção está pautada em um modelo agroalimentar mais saudável e sustentável, do ponto de vista econômico e ambiental, aproximando a relação produção-consumo e enfatizando a produção da AF. Nesses termos, o objetivo do PNAE passa a ser o de "suprir parcialmente as necessidades nutricionais dos alunos, com vistas a garantir a implantação da política de Segurança Alimentar e contribuir para a formação de bons hábitos alimentares" (resolução n. 15 de 16/06/2003). Em 2006, o PNAE contemplou o apoio ao desenvolvimento sustentável, ao fortalecer/incentivar as culturas locais ${ }^{13}$.

Essa nova concepção toma corpo quando da promulgação da Lei $n$. 11.947/2009, que obriga a aplicação de no mínimo 30\% dos recursos advindos do FNDE na aquisição de alimentos da AF. Essa lei prevê, ainda, processos de compra menos burocráticos, se comparados com a lei de licitações brasileira (Lei n. 8.666/1993)14. Deve-se ressaltar que, além dos recursos do FNDE, os estados e municípios podem ampliar esses valores, na medida em que a legislação estabelece que devam direcionar o mínimo de $25 \%$ de sua receita para despesas em educação. Outra possibilidade é o fato de que esses entes podem, por meio de suas legislações, ampliar algumas regras, como, por exemplo, a instituição da merenda escolar orgânica, realizada pelo Estado do Paraná (Lei Estadual do Paraná n. 16.751/2010).

Passados mais de cinco anos da Lei 11.947/2009, percebe-se que nem todos os entes federados já se adequaram a essa legislação (conforme dados apresentados na introdução), e alguns estudos foram, e vem sendo, realizados, na perspectiva de

\footnotetext{
${ }^{13}$ A obra de Bhargava (2008) traz uma resenha de vários estudos em nível internacional que traduzem os impactos positivos de uma alimentação saudável sobre desempenho escolar e sobre indicadores de saúde.

${ }^{14}$ Para Grisa e Porto (2015), a Lei n. 8.666/1993 restringe as possibilidades de SAN e de fortalecimento da AF, pois inviabiliza o pequeno produtor de concorrer nas licitações, estimulando grandes grupos alimentares do país, com alimentos de qualidade duvidosa e externos aos hábitos regionais.
} 
avaliar a efetivação e os efeitos dessa política. Na intenção de sintetizar alguns resultados desses trabalhos, serão apresentados, na sequência, os principais aspectos positivos e as maiores dificuldades na implementação da política, que servirão de base comparativa com a nossa pesquisa.

Em relação aos efeitos positivos da política, a literatura pesquisada é unânime em afirmar que tem ocorrido a geração e ampliação de renda para a AF e a melhoria da alimentação dos estudantes, conforme demonstraram os trabalhos de Belik et al (2011) e Triches (2015). Outro ponto destacado é o resgate da cultura alimentar regional, uma vez que os cardápios passam a ser formados a partir dos gêneros produzidos na região. Como consequência desse resgate, Monego et al (2013) expõem que há a valorização do trabalho dos agricultores, pois começam a ser vistos como importantes agentes da SAN, fortalecendo ações de educação nutricional (muitas escolas fazem visitas com alunos às propriedades).

Por fim, Constanty (2014) observou que ocorre também a diversificação da cesta de produtos que passaram a ser produzidos nas propriedades, contribuindo tanto para ampliar a renda, como para melhorar a alimentação da própria família do agricultor. Ainda no tocante à produção, percebeu-se o estímulo à cooperação, a busca por novos mercados (feiras e abastecimento de supermercados locais) e a ampliação de iniciativas de produção orgânica.

Contudo, apesar dos grandes benefícios, a nova configuração do PNAE ainda encontra alguns desafios para se consolidar como uma ferramenta mais efetiva de DR e garantir maiores impactos. Neste sentido, podem-se apontar como principais dificuldades as questões operacionais, a estrutura da oferta, as regulamentações sanitárias e questões políticas.

As questões operacionais estão relacionadas à organização da gestão do Programa por parte dos entes federados. Segundo Triches et al (2018), a falta de diálogo entre os diferentes setores da administração pública local, aliada às dificuldades de logística de distribuição dos produtos e refeições, limita o potencial de demanda. Dentro dessa questão, os autores apontam que a rigidez dos cardápios, influenciada por uma cultura conservadora por parte de nutricionistas, interfere diretamente na cesta de produtos demandados da AF.

Na esfera da produção, conforme Baccarin et al (2011) e Ribeiro et al (2013), muitos municípios enfrentam a oferta insuficiente de produtos para a alimentação escolar, tendo em vista que as propriedades estavam estruturadas para atender o modelo de agricultura tradicional (commodities). Nesses termos, a organização dos produtores e uma política de Assistência Técnica e Extensão Rural (ATER) mais específica poderiam contribuir para ampliar a produção.

No que tange a regulação sanitária, existem, ainda, muitas dificuldades em se adequar à legislação (regulamentações sanitárias, fiscais e ambientais nacionais, que ditam as regras a serem seguidas em todo o território nacional), em virtude de que, em muitos casos, a adequação exige investimentos nem sempre suportados pela AF ou pelas cooperativas (TRICHES ET AL., 2018; COSTA et al, 2015). Já as questões políticas estão relacionadas com a falta de interesse de muitos entes nos programas, o que faz com que não sejam dedicados esforços em organizá-los (há casos em que o preparo da alimentação escolar é terceirizado para empresas privadas e/ou toda a operacionalização fica a cargo das nutricionistas). Essa questão é ampliada pela 
atuação incipiente dos CAEs e Conselhos de Segurança Alimentar (CONSEA) (TRICHES, 2015).

\section{Metodologia}

Para avaliar o desempenho do PNAE, o presente trabalho lançou mão de um estudo de caso nos municípios pertencentes às microrregiões de Chapecó, Concórdia e Xanxerê, as quais compreendem a mesorregião Oeste de Santa Catarina. As três microrregiões se constituem de 70 municípios e correspondem a 59\% dos municípios do Oeste. Em 2014, as três microrregiões detinham cerca de 47 mil alunos matriculados na rede municipal de ensino, conforme o Censo Escolar.

A escolha desse recorte regional decorre por conta de essa região apresentar uma significativa presença da AF, advinda de uma história de colonização em pequenas propriedades, tornando-se o principal capital social regional. A AF, nessa região, tem passado por transformações profundas durante as últimas três décadas, como resultado da exclusão de milhares de agricultores e do consequente êxodo destes. Em razão disso, a região se torna um ambiente (lócus) adequado para avaliar os efeitos de uma política pública voltada para a AF, e por sua vez, para o DR.

A pesquisa realizada pode ser classificada como explicativa (pois busca identificar fatores que determinam ou contribuem para o desempenho do PNAE na região Oeste), desenvolvendo uma abordagem qualitativa. O método de pesquisa empregado foi o estudo de caso, que, segundo Yin (2009), é uma estratégia empírica utilizada para compreender profundamente um fenômeno da vida real dentro do seu contexto, com base numa metodologia específica de plano de pesquisa, técnicas de coleta de dados e abordagem na análise de dados. Ainda segundo o autor, esse método permite ao pesquisador capturar vários processos envolvidos no contexto social sob análise, no qual essas interações estão ocorrendo.

Portanto, a abordagem do estudo de caso foi utilizada como uma estratégia para compreender como os municípios se comportaram para operacionalizar o mercado institucional criado pela Lei n. 11.947/2009 e levantar quais os principais benefícios e desafios desse marco legal. Nesse sentido, o estudo de caso procurou analisar efeitos de uma política pública que apresenta objetivos multidisciplinares, como o fortalecimento da AF, a SAN e, consequentemente, o DR.

Como instrumentos de coleta das informações primárias (utilizados de forma conjunta no processo de análise), foram realizadas entrevistas semiestruturadas junto aos responsáveis pela operacionalização do PNAE nas prefeituras municipais e, complementadas através de fóruns que contou com a presença destas prefeituras e também em alguns casos, das cooperativas da AF que participam diretamente dessa operacionalização nos municípios ${ }^{15}$.

As entrevistas foram executadas da seguinte forma: inicialmente foram enviados convites com os questionários da entrevista (e os termos de aceite de participação à pesquisa) para as 70 prefeituras que compõem as três microrregiões de análise. Na sequência, foram realizadas cinco oficinas regionais ao longo do mês

\footnotetext{
${ }^{15}$ A coleta de informações a partir dos fóruns se assemelha muito com a técnica de grupos focais, técnica muito utilizada em Ciências Sociais e Sociais Aplicadas e que consiste na formação de um grupo reduzido de indivíduos reunidos para avaliar conceitos e identificar problemas (CRUZ NETO et al, 2008).
} 
de novembro de 2015, nas cidades de Chapecó, Pinhalzinho, Formosa do Sul, São Domingos e Seara. Essas oficinas foram estruturadas no formato de fóruns, nos quais as prefeituras foram convidadas a debater o PNAE e expor suas experiências. Ao final dos fóruns, era finalizada as entrevistas com cada uma das prefeituras. Essa metodologia se revelou oportuna, na medida em que se pode reunir um grupo maior de sujeitos no mesmo espaço e ampliar o nível de observação dos casos, principalmente quando foram confrontados com experiências de municípios vizinhos.

Os questionários aplicados foram construídos com base na literatura de $\mathrm{DR}$, à luz da Lei n. 11.947/2009 (bem como suas resoluções n. 26/2013 e n. 4/2015) e por meio de debates com cooperativas da AF e representantes sindicais da AF. Por fim, a adequação do questionário foi verificada em estudo preliminar (piloto) realizado com três prefeituras da microrregião de Chapecó, no mês de julho de 2015.

Tabela 1 - Sumário estatístico dos municípios pertencentes à amostra e comparativo com o estado de Santa Catarina - 2012

\begin{tabular}{l|c|c|c|c|c}
\hline \multirow{2}{*}{ Indicador } & \multicolumn{3}{c|}{ Municípios da Região } & Total Região da & \multirow{2}{*}{ Estado de SC } \\
\cline { 2 - 4 } & media & min & max & 432.223 & 6.383 .286 \\
População & 13.943 & 1.698 & 198.188 & 100.493 & 1.000 .523 \\
Pop. Rural & 3.242 & 961 & 16.162 & 23,25 & 15,67 \\
\% Pop. Rural & 50,93 & 8,15 & 83,60 & 19.119 & 143.542 \\
Nr. DAPs & 617 & 268 & 2.059 & 26 & 182 \\
Nr. Cooperativas & 0,84 & 0 & 4 & 10.746 .131 & 177.275 .691 \\
PIB * & 346.649 & 20.212 & 5.259 .307 & 657.649 & 6.388 .653 \\
PIB Agrícola* & 21.214 & 6.286 & 79.616 & 6,2 & 3,6 \\
\% PIB rural & 24,22 & 0,9 & 53,1 & 24.862 & 19.070 \\
PIB per capita & 17.553 & 10.346 & 37.944 & & 0,774 \\
IDH-M** & 0,732 & 0,597 & 0,800 & & \\
\hline
\end{tabular}

Fonte: Elaboração dos autores, a partir de dados do IBGE, MDA e IPEA/2015. * Em R\$ mil. **Refere-se ao ano de 2010.

Foram três aspectos que motivaram a escolha das prefeituras (municípios) como unidade de análise da pesquisa. O primeiro decorre de que os municípios são os principais agentes de operacionalização dessa política pública, sendo, portanto, os principais responsáveis pelo sucesso (ou não) da política. O segundo elemento refere-se à possibilidade (ou objetivo) de avaliar o volume da demanda de alimentos em cada município, podendo, assim, contribuir para o melhor planejamento da produção por parte dos demais atores que participam do PNAE. O terceiro refere-se ao fato de que, em virtude do Governo de Santa Catarina terceirizar a alimentação escolar nas escolas sob sua gestão, as compras da AF não são realizadas nos municípios das escolas estaduais, e a análise fica prejudicada.

Considerando essas premissas metodológicas, a pesquisa realizou 31 entrevistas, o que representa $44 \%$ do total de municípios das três microrregiões objeto de estudo. Na Tabela 1 há um sumário estatístico dos municípios participantes da pesquisa. A tabela expõe algumas características socioeconômicas dos municípios pesquisados e compara com o estado de Santa Catarina.

Fazendo a leitura apenas para a variável percentual da população rural (“\% pop rural”), verifica-se que, em média, os 31 municípios da amostra têm mais de 50\% de sua população vivendo na zona rural, apresentando um mínimo de 8,15\% 
(representada pelo município de Chapecó, a maior cidade e mais urbanizada da região) e um máximo de $83,6 \%$ em Santa Terezinha do Progresso. No estado, esse percentual é de $15,7 \%$. Esse dado revela um pouco do traço rural que é caracterizado na amostra da pesquisa.

\section{Análise dos resultados}

A presente seção visa a apresentar e analisar os resultados da pesquisa. Para uma melhor exposição da análise, a seção está dividida em quatro partes. A primeira discutirá o perfil das compras das prefeituras. A segunda avalia a operacionalização do Programa no município, como ações que são desenvolvidas junto a AF para organizar a produção. A terceira apresenta aspectos relacionados às escolas que recebem os alimentos, bem como avalia a transversalidade do tema da alimentação nos planos educacionais. A quarta parte analisa os principais pontos positivos e limitadores do Programa. Em virtude do espaço do trabalho, não apresentaremos tabelas e gráficos de todas as 26 questões de nosso instrumento de coleta de dados, e muitas respostas estão apresentadas de forma intercalada.

\section{Perfil das compras do PNAE municipal da AF}

O primeiro aspecto levado em consideração em nossa pesquisa se refere aos recursos do FNDE direcionados à aquisição de produtos da AF. Nesse sentido, verificou-se que apenas um dos municípios não vem conseguindo adquirir da AF o valor mínimo de 30\% dos recursos, conforme especificado pela Lei n. 11.947/2009. Os demais estão superando esse percentual, e muitos estão direcionando esforços para ampliar anualmente as compras da AF. Verificou-se que, no ano de 2009, em média $39,2 \%$ dos recursos do FNDE eram direcionados para aquisição da AF, ampliando-se para $68,4 \%$, em $2014^{16}$.

Essas informações foram repassadas pelas próprias prefeituras, e existem pequenas diferenças em comparação aos dados fornecidos pelo FNDE. Chamou atenção a dificuldade apresentada pelos municípios no fornecimento de tais informações desagregadas (nesse caso, cinco prefeituras não responderam e 10 prefeituras responderam de forma incompleta). Essas dificuldades geralmente estão relacionadas às diferentes formas das Prefeituras classificarem tais informações. Por exemplo, como os recursos do FNDE não cobrem toda a despesa com alimentação escolar no município, as administrações precisam aportar recursos adicionais, e essa divisão não fica clara quando se avalia o montante total direcionado para a AF. Essa falta de informações pode ser considerada como uma fraqueza da gestão do Programa, pois limita seu acompanhamento no tempo, dificulta o planejamento das ações e, além disso, limita a análise e avaliação da política.

${ }^{16} \mathrm{Em}$ que pese a legislação facultar a aquisição de alimentos de agricultores familiares de municípios vizinhos, os números apresentados referem-se a um mínimo de $90 \%$ de aquisições de agricultores do próprio município. A diferença é decorrente de compras de cooperativas de $\mathrm{AF}$, que podem possuir produtos de agricultores de outros municípios. Por outro lado, agricultores dos municípios em análise, por estar vendendo para municípios vizinhos, quando participam de uma cooperativa. 
Em relação aos produtos adquiridos da AF, foram classificados em "in natura" e "processados", em um total de 82 alimentos. Os produtos "in natura" são 45 itens, sendo 29 verduras/legumes e/ou cereais e 16 frutas, com destaque para os seguintes produtos: alface, repolho, beterraba, laranja, cenoura, batata-doce, couve-flor, bergamota e mandioca. Já os "processados" englobam 37 itens, tendo destaque a bolacha caseira, mandioca descascada, pão caseiro, açúcar mascavo, cuca/bolo e macarrão caseiro.

Considerando esses números, verificou-se que a quantidade e diversidade de itens foram se ampliando a cada ano, demonstrando por um lado a preocupação em diversificar e incluir novos tipos de alimentos oferecidos nas escolas e, por outro, 0 estímulo do agricultor em explorar novas culturas, bem como, o papel da agregação de valor ao produto, quando considerada a demanda por produtos transformados ${ }^{17}$.

Dentro da esfera da compra de alimentos, há preferência por produtos orgânicos e agroecológicos em 19 municípios (61\% da amostra). Seis municípios (20\%) que não manifestaram preferência justificaram que tais produtos necessitam de certificação, e, no momento, os agricultores do município ainda não a possuem. A pesquisa demonstrou que há demanda por tais produtos, mas são enfrentadas dificuldades em termos de baixa oferta (ou em alguns casos, a inexistência desses produtos), principalmente em virtude da falta de certificação.

Apesar de crescente, as prefeituras destacaram que há espaço para ampliar a demanda geral de produtos da AF, porém é necessário avultar a oferta. O estudo identificou escassez de oferta, principalmente nos seguintes produtos: arroz, feijão, carnes (frango, gado e suíno), bebidas lácteas, farinha de milho, maçã, mamão e geleia de frutas. Alguns desses itens, por necessitarem de legalização/inspeção, principalmente carnes e lácteos, acabam gerando restrições para a oferta pela AF.

As prefeituras manifestaram, ainda, a preocupação com a qualidade dos produtos adquiridos, sendo que $75 \%$ dos municípios exigem certificação e/ou registro dos produtos, e $90 \%$ os inspecionam tecnicamente e exigem embalagens adequadas. Apenas dois municípios não fazem nenhum tipo de exigência aos produtores.

Com relação ao número de agricultores familiares que estão envolvidos na oferta ao PNAE, a pesquisa levantou 402 agricultores, sendo que nove municípios não responderam (ou não possuem cadastro/históricos dos agricultores que participaram do Programa), o que leva esse número a ser bem maior. Cabe destacar aqui o papel das cooperativas da AF, existentes em muitos municípios, que contribuem para organizar a produção, a documentação das chamadas públicas e a logística de entrega dos produtos nas escolas. Muitas dessas cooperativas nasceram com o objetivo de organizar a produção para atender os mercados institucionais (PAA e PNAE) e tiveram apoio de outros programas (Projeto Territórios). Atualmente, muitas vêm desenvolvendo empreendimentos de processamento dos produtos "in natura", como, por exemplo, panificados e biscoitos, sucos e geleias, carnes e embutidos e lácteos.

\section{Gestão do Programa pelas prefeituras}

\footnotetext{
${ }^{17}$ A preocupação em diversificar e incluir novos alimentos no cardápio escolar pode ser avaliada pelas ações realizadas entre poder público, nutricionistas e cozinheiras, como a realização de concursos de receitas entre as cozinheiras das escolas coordenado pelas associações de municípios.
} 
Conforme apontado na revisão de literatura, um aspecto fundamental para o sucesso do Programa e inserção da AF é o comprometimento/engajamento dos municípios na gestão do Programa. Como gestão ou governança, entende-se o envolvimento do município em todas as etapas do processo de compra (que vai desde a pesquisa dos produtos existentes no município e das reuniões de divulgação com a AF) até o acompanhamento da produção, a gestão da logística e o envolvimento com os planos educacionais das escolas, tendo em vista a importância do tema da SAN. Por fim, a gestão do Programa também exige monitoramento e socialização dos resultados junto à comunidade e/ou controle social.

Verificou-se ao longo das respostas, que este tem sido o principal gargalo do Programa. Em 90\% dos municípios pesquisados, a gestão é "terceirizada" para as nutricionistas, responsáveis técnicas do Programa ${ }^{18}$. Também não há o envolvimento das Secretarias diretamente afetadas pelo PNAE, como as secretarias da Agricultura e da Educação. Esse comportamento tem efeitos diretos sobre a efetividade do Programa e gera a perda de uma oportunidade única para estimular o desenvolvimento socioeconômico do município.

Nesse sentido, buscou-se identificar ações (projetos ou programas) que as prefeituras desenvolvem para estimular e planejar/organizar a produção da AF para o mercado institucional da alimentação escolar do PNAE. Verificou-se, conforme exposto pelo Quadro 1, que 23 municípios ( $74,2 \%$ da amostra) realizaram alguma ação de incentivo e de organização da produção. No entanto, percebeu-se que há constante falta de articulação entre as Secretarias envolvidas (Agricultura e Educação) e, na maioria dos casos, essas ações são repassadas para as cooperativas da AF (20 municípios desenvolveram parecerias com cooperativas da AF), embora elas não tenham condições financeiras e infraestrutura para realizarem algumas ações importantes, como ATER para a AF.

Em virtude dessa realidade, optou-se em classificar as ações municipais em três tipos de ações (fraca, média e forte). As ações consideradas “fracas" são aquelas em que as Prefeituras apenas divulgam os processos de chamada pública e fazem visitas pontuais para estimular a produção para o PNAE. As ações classificadas como "médias" incluem uma preocupação maior com a AF e procuram envolver outras entidades ligadas à agricultura, como Cooperativas, Sindicatos da Agricultura Familiar e Epagri. As ações “fortes” são aquelas consideradas mais próximas do ideal no que concerne a promover a ampliação da oferta de alimentos para o PNAE e melhorar as condições de produção dos agricultores, como a organização da produção, apoio logístico e ATER específica.

Quadro 1 - Ações e programas realizados pelas Prefeituras para auxiliar a AF na oferta de produtos ao PNAE

\begin{tabular}{|c|l|c|}
\hline Tipo de Ação & \multicolumn{1}{|c|}{ Caracterização } & $\begin{array}{c}\text { Quantidade de } \\
\text { respostas }\end{array}$ \\
\hline Fraca & $\begin{array}{l}\text { Restringe-se a visitas de “animação" nas } \\
\text { propriedades rurais. }\end{array}$ & 5 \\
\hline Média & $\begin{array}{l}\text { Realização de parcerias com outras } \\
\text { instituições (Cooperativas, Sindicatos, }\end{array}$ & 14 \\
\hline
\end{tabular}

${ }^{18}$ Apesar de a gestão ficar a cargo quase que estritamente das nutricionistas, percebeu-se que as mesmas possuem envolvimento com o Programa, se esforçando em incluir a AF. Resultados diferentes daqueles encontrados por Constanty (2014). 


\begin{tabular}{|c|l|c|}
\hline & $\begin{array}{l}\text { Sebrae, Epagri) e de algumas ações mais } \\
\text { específicas. }\end{array}$ & \multicolumn{1}{|c|}{4} \\
\hline Forte & $\begin{array}{l}\text { A prefeitura lidera projetos de } \\
\text { mobilização da AF com ações reais/de } \\
\text { impacto. }\end{array}$ & 7 \\
\hline Não realiza & Não desenvolve nenhuma ação. & \multicolumn{1}{|c|}{1} \\
\hline Sem resposta & & \\
\hline
\end{tabular}

Fonte: elaboração dos autores, a partir dos dados da pesquisa.

Por meio da análise dos dados coletados, percebeu-se que apenas quatro municípios realizaram uma gestão completa ou ações de cunho "forte" (conforme definição acima) e iniciaram projetos de envergadura para gerar resultados reais e sustentáveis para a AF. Nesse rol de iniciativas, teve-se a criação de coordenação do PNAE dentro da Secretaria de Agricultura, em que foram disponibilizados funcionários para acompanhar todo o processo de aquisição dos alimentos, logística e realização de interfaces com as escolas. Ligada à criação da coordenação, houve a constituição de uma central de recepção dos alimentos para posterior distribuição nas escolas, com veículo próprio da coordenação. Outras ações incluíram disponibilidade de técnico agrícola para realização de ATER específica ao PNAE aos agricultores e inclusão de normativas na legislação municipal para ampliar o percentual de aquisição da AF dos recursos do FNDE $^{19}$.

Uma terceira iniciativa foi a realização de projeto de certificação de produtos orgânicos, em parceria com Instituto de Desenvolvimento Regional, institucionalização de programas de capacitação junto a AF, bem como planejamento da produção com os agricultores. Por fim, teve-se ações lideradas pelas secretarias de agricultura e de educação, que envolvem todo o município, como o "Setembro Verde", semana do mês de setembro dedicada à sensibilização a respeito da alimentação saudável e proteção do meio ambiente.

Nas ações de grau médio, podem-se destacar as constantes melhorias e adaptações do cardápio para priorizar a produção da AF local, envio ao legislativo de proposta de Plano Diretor Rural do município - com programas específicos para a AF -, campanhas de capacitação da AF para o PNAE e apoio logístico para as cooperativas da AF. Em sete municípios, não houve a realização de nenhuma ação voltada ao PNAE. Essa falta de protagonismo das prefeituras acaba refletindo na baixa participação da $A F$, no baixo impacto socioeconômico regional e na ineficácia da SAN.

Outras questões da pesquisa também demonstraram o baixo engajamento dos municípios, como, por exemplo, o escasso apoio de ATER na produção de itens da alimentação escolar. Nesse quesito, 17 municípios (55\%) não realizaram qualquer tipo de ATER e 10 municípios (32\%) realizam ATER por meio de parcerias com cooperativas e/ou empresas de pesquisa (que em alguns casos não é uma ATER específica). Apenas cinco municípios (13\%) realizaram ATER específica (considera-se aqui ATER específica, o direcionamento de um técnico agrícola para assessorar famílias que participam do Programa).

Em termos de suporte logístico aos agricultores para coleta, armazenagem e distribuição dos produtos (elemento importante na formação dos custos de

${ }^{19} \mathrm{O}$ município que ampliou a legislação, também venceu o prêmio nacional gestão eficiente da alimentação escolar nos anos de 2010, 2012 e 2013. 
produção). Verificou-se que $46 \%$ das respostas remetem para o agricultor a total execução desse serviço e, em $28 \%$, fica a cargo do produtor levar até uma central do município. Aqui ficou evidenciado o apoio das cooperativas, já que, em $20 \%$ das respostas, estas são responsáveis pela logística do Programa. Apenas um município faz a coleta diretamente na propriedade do agricultor.

Muitos municípios responderam que não forneceram auxílio ou realizaram maiores ações, em decorrência do fato de que sua demanda para o PNAE é muito pequena. Porém, ao confrontar com outras questões da pesquisa, percebeu-se que tais prefeituras também não se engajaram em parcerias com municípios vizinhos para realização de projetos conjuntos, que proporcionariam a ampliação da escala de produção da AF.

Ao serem avaliados alguns aspectos administrativos (elaboração da chamada pública, por exemplo), verificou-se que, em 21 municípios, o método para calcular o preço pago ao produtor segue os pressupostos mínimos da Lei 11.947/2009, pois apenas fazem o cálculo mediante pesquisa de preços em três estabelecimentos locais. Outros oito municípios procuram, além da pesquisa de preços, considerar outros custos envolvidos na transação, como o custo com transporte $\mathrm{e}$ administrativos. Dois municípios não responderam.

Tal metodologia de cálculo do preço é relevante para garantir que o agricultor tenha retorno positivo, isto é, a geração de renda para a AF. Dessa maneira, para avaliar a efetividade da metodologia de cálculo, foi questionado se os municípios tinham conhecimento da margem de lucro dos agricultores, dos quais 19 municípios alegaram que acreditam haver retorno positivo (embora não mencionassem nenhuma metodologia de cálculo desse retorno). Outros 12 municípios não sabem ou não responderam.

Os municípios também consideraram que não há diferenças entre as chamadas públicas e os leilões eletrônicos (formas alternativas de compra da AF e dos mercados convencionais, respectivamente), e que, quando há diferença, esta é em prol da AF. Apenas quatro municípios não responderam e um município mencionou que a única diferença ocorre quando se trata de produto orgânico. Em se tratando dos processos de compra, ficou nítido o distanciamento das equipes técnicas das prefeituras com a realidade dos agricultores e a falta de interesse em compreender essa realidade e de adaptar os processos burocráticos para facilitar a compra dos agricultores. Neste quesito, há um longo caminho para mudar a cultura dos servidores municipais.

Interação entre alimentos da AF e as escolas

A preocupação com a SAN é um dos objetivos fundantes/estruturantes da Lei n.11.947/2009. Nesse contexto, o efeito de uma alimentação saudável, evidenciado no melhor desempenho escolar e saúde dos alunos é um princípio básico do PNAE. Procurou-se, então, analisar em que medida a aquisição dos alimentos da AF se constitui em uma interface com as escolas. Para tanto, foi avaliado como se dá a preparação da alimentação escolar. Em 28 municípios, a preparação é realizada nas escolas ou em unidades do município, com equipes de cozinheiras e funcionárias municipais, monitoradas pelas nutricionistas. Apenas em dois municípios a preparação da comida é terceirizada, e um município não respondeu. Em todas as 
escolas em que há preparação própria, há estruturas de freezers e atendimento às especificações técnicas do local e equipamentos.

O acompanhamento dos estudantes referente a preferências por alimentos, satisfação da merenda fornecida, educação alimentar, ganhos de peso e/ou melhoria do desempenho na escola foi realizado por 29 municípios, e dois não responderam ${ }^{20}$. O acompanhamento foi realizado pelas nutricionistas, por meio de testes de aceitabilidade, toda vez que muda o cardápio (nesse caso, há preocupação em alterar e encontrar formas alternativas de inserir legumes/frutas para despertar o interesse dos alunos) e de oficinas de educação alimentar. Em alguns poucos casos, houve parcerias com o Programa Saúde na Escola e a realização de avaliação antropométrica, com auxílio dos professores de educação física.

Por fim, buscou-se analisar se os planos municipais de educação contemplavam atividades interdisciplinares com relação à alimentação saudável (produção agroecológica, valorização da agricultura familiar), ou se as coordenadoras pedagógicas das escolas realizavam ações voltadas a esses aspectos. Em 20 municípios, há essa correspondência, seis não realizam, e cinco não responderam à questão. Uma ação que se destaca é a visitação de alunos a propriedades rurais, visando a aproximar as crianças da AF e valorizando o trabalho dos agricultores.

Avaliação geral do Programa (pontos positivos e limitações)

A quarta dimensão de análise refere-se à percepção dos municípios com relação aos efeitos da criação do mercado institucional para AF via PNAE, bem como ao levantamento dos principais desafios para a sustentabilidade do Programa. Considerou-se, aqui, que o constante monitoramento do desempenho das políticas públicas é instrumento fundamental para seu aprimoramento e avanço. O Quadro 2 apresenta uma síntese dos principais pontos destacados pelos 31 municípios envolvidos na pesquisa.

Quadro 2 - Percepção dos principais benefícios e desafios do PNAE (Lei n.11.947/2009) nos municípios

\begin{tabular}{|l|c|l|c|}
\hline \multicolumn{1}{|c|}{ Benefícios } & $\begin{array}{c}\text { Qtde } \\
\text { Resp. }\end{array}$ & \multicolumn{1}{|c|}{ Desafios } & $\begin{array}{c}\text { Qtde } \\
\text { Resp. }\end{array}$ \\
\hline $\begin{array}{l}\text { a) Efetivação da SAN e melhoria da } \\
\text { qualidade da alimentação escolar }\end{array}$ & 24 & $\begin{array}{l}\text { a) Falta de oferta e/ou produção de } \\
\text { alimentos para a alimentação escolar em } \\
\text { quantidade insuficiente }\end{array}$ & 13 \\
\hline b) Fortalecimento da AF local & 16 & $\begin{array}{l}\text { b) Sazonalidade dos produtos e logística } \\
\text { (entrega, armazenamento, embalagem) }\end{array}$ & 7 \\
\hline
\end{tabular}

${ }^{20}$ Conforme a Lei n. 11.947/2009, os municípios são obrigados a realizar tais acompanhamentos e avaliações, porém nenhum apresentou algum resultado específico desses acompanhamentos. 


\begin{tabular}{|l|c|l|c|}
$\begin{array}{l}\text { c) Desenvolvimento local e } \\
\text { regional (renda, emprego) }\end{array}$ & 12 & $\begin{array}{l}\text { c) Outros problemas relacionados com } \\
\text { agricultores (desinteresse, } \\
\text { descompromisso) }\end{array}$ & 5 \\
\hline $\begin{array}{l}\text { d) Estímulo para permanência do } \\
\text { jovem no campo }\end{array}$ & 4 & $\begin{array}{l}\text { d) Falta de ações do município para } \\
\text { organizar a produção junto a AF }\end{array}$ & 3 \\
\hline e) Desenvolvimento sustentável & 2 & $\begin{array}{l}\text { e) Dificuldades na legalização/inspeção de } \\
\text { produtos transformados }\end{array}$ & 2 \\
\hline f) Incentivo ao cooperativismo & 2 & f) Falta de diversidade de produção; & 2 \\
\hline g) Desenvolvimento rural & 1 & $\begin{array}{l}\text { g) Baixa demanda do município não } \\
\text { incentiva aumento da produção pela AF }\end{array}$ & 2 \\
\hline $\begin{array}{l}\text { h) Estímulo a outras redes de } \\
\text { comércio/consumo (feiras) }\end{array}$ & 1 & h) Baixa qualidade dos produtos entregues & 2 \\
\hline $\begin{array}{l}\text { i) Melhoria do desempenho escolar } \\
\text { dos alunos }\end{array}$ & 1 & $\begin{array}{l}\text { i) Excesso de trâmites/documentos } \\
\text { (burocracia) }\end{array}$ & 2 \\
\hline j) Melhora das finanças públicas & 1 & & \\
\hline
\end{tabular}

Fonte: elaboração dos autores, a partir dos dados da pesquisa. Obs.: cada prefeitura pôde escolher mais de uma opção.

Sobre os benefícios gerados pelo Programa, percebeu-se um consenso em relação a três pontos: o reconhecimento de que o Programa possibilitou a disponibilidade de alimentos mais saudáveis, contribuindo com a saúde dos alunos; o fortalecimento da AF do município, pois propiciou mais uma alternativa de renda ao agricultor; e o estímulo da economia local, em virtude de que os recursos do FNDE passaram a circular no município.

Quanto ao primeiro, pode-se acrescentar, ainda, que a proximidade com o produtor facilitou o contato e ajuste do produto à necessidade da escola e favoreceu a realização de visitas com os alunos. Além disso, o uso de alimentos saudáveis e de origem local facilitou a construção de uma nova cultura alimentar mais saudável.

Os aspectos aqui analisados deixam entrever que o fortalecimento da AF vai para além da geração de renda, pois, em alguns municípios, a organização da produção para o PNAE contribuiu para a formação de feiras na cidade. Outros municípios apontaram que os jovens começaram a perceber oportunidades para seguir na propriedade.

Por fim, agrega-se ao fator de desenvolvimento local o aumento na arrecadação municipal em virtude da geração de renda dos agricultores (bem como gastos no comércio e prestação de serviços) e potenciais melhorias da saúde no município (em virtude da alimentação saudável), que podem propiciar economia nas despesas com consultas/remédios.

Ao comparar tais resultados aos demais estudos sobre o PNAE referenciados no texto, evidencia-se que há uma estreita relação entre eles, sugerindo que tais estudos sejam utilizados para elaborar novos mecanismos para aprimorar o Programa e inserir uma quantidade maior de agricultores. Por outro lado, fica evidente que a construção do mercado institucional via PNAE foi uma política muito eficaz em torno dos seus objetivos e só não apresenta resultados mais amplos em virtude de limitações em sua governança, questão que pode ser melhorada.

Com relação às dificuldades enfrentadas pelo programa, foi apontado como principal problema, a falta de oferta de gêneros da alimentação escolar, tanto em relação ao número de agricultores que se dediquem a tal cultivo, quanto pela falta de variedade 
de produtos, incluindo produtos orgânicos. Esse problema pode ter sua explicação por outros motivos apontados como limitadores do PNAE, como a falta de assessoria/apoio por parte dos municípios (já mencionado na revisão de literatura), falta de apoio logístico, baixa demanda em alguns municípios, dificuldades na inspeção/legalização de produtos e excesso de trâmites. Todos esses fatores acabam desmotivando os agricultores a adentrarem nesse mercado institucional.

Outras causas para a pequena oferta podem estar relacionadas a escassez de mão de obra no campo (a região Oeste vive uma acelerada perda da população rural), as restrições de ATER para lidar com tais gêneros e a dificuldade do agricultor familiar lidar com questões burocráticas, isto é, a necessidade de reunir um conjunto de documentos e preenchimento de formulários para participar das chamadas públicas, pode desmotivar os pequenos agricultores. É nesse quesito que se observa o papel destacado das cooperativas da AF, em termos de poderem organizar e assessorar a produção. A presença das cooperativas da agricultura familiar foi considerada fundamental pelos agentes públicos para o avanço do mercados institucional do PNAE. Em que pese a importância dessas cooperativas, sua ação poderia ser mais efetiva, na medida em que tivessem estrutura ou que o município se responsabilizasse pela ATER.

Com relação ao aspecto "outros problemas relacionados ao agricultor", foram apontadas as dificuldades do agricultor em seguir o cronograma (esquecimento da data de entrega) e/ou a desistência em participar do Programa após terem sido aprovados na chamada pública. Outros indicaram a falta de compreensão dos agricultores sobre o PNAE, gerando um distanciamento do agricultor e do Programa. Desta forma, percebe-se que a maior parte dos problemas enfrentados na condução do PNAE e listados pela literatura, também se verificaram no Oeste Catarinense, o que enseja a necessidade de aprimoramento do Programa.

\section{Conclusões}

O presente estudo procurou analisar a nova modalidade do PNAE, que prevê o direcionamento de parte dos recursos do FNDE para a aquisição de alimentos da AF, por meio de sua governança pelas prefeituras municipais em três microrregiões do Oeste de Santa Catarina. Essa região se mostrou adequada para a análise por contemplar grande participação da AF, a qual vem enfrentando dificuldades nos últimos anos em virtude dos efeitos das exigências de novos modos de produção do mercado convencional.

$O$ estudo demonstrou que o PNAE se insere em uma iniciativa de DR que vem ganhando corpo internacionalmente e que as políticas públicas são fundamentais para seu desempenho de longo prazo. Nesse sentido, a Lei n. 11.947/2009 inova, no sentido de contemplar no tema da alimentação escolar as premissas da SAN e do DR, ao estimular a AF. Dessa forma, muitos resultados positivos já estão sendo verificados em todo o país.

Acredita-se que esta pesquisa tenha contribuído com a avaliação do Programa, demonstrando que ele vem atingindo seus principais objetivos, em termos de fortalecimento da AF, melhoria na qualidade nutricional para os alunos e, também, na medida em que se constitui como promotor do desenvolvimento local/regional. Nesse sentido, a política vem se demonstrando eficaz. 
Percebeu-se, porém, que algumas situações vêm restringindo maiores impactos do Programa, como é o caso da Governança municipal. No tocante ao problema em apreço, a pesquisa verificou que apenas quatro prefeituras (13\% de nossa amostra) realizaram uma gestão do Programa considerada adequada, no que concerne a desenvolver ações de organização da produção, auxílio logístico e assessoria técnica aos agricultores. Nas demais prefeituras, ficou transparente a falta de envolvimento e articulação dos produtores, sendo que, em muitos casos, a gestão do Programa ficou a cargo das nutricionistas, sem maior participação das secretarias envolvidas (Educação e Agricultura). Uma ação que relativiza a falta de engajamento das prefeituras é a atuação realizada pelas cooperativas da AF, o que pode ser evidenciado pelo fato de que, em muitos municípios, são as cooperativas que organizam a produção e dão suporte administrativo e logístico.

Essa realidade pode explicar um segundo gargalo do Programa: a falta de oferta de produtos para alimentação escolar. Deve-se ponderar que essa baixa oferta tem forte relação com a falta de assessoria e de apoio logístico, baixa demanda por parte de alguns municípios, dificuldades na inspeção/legalização de produtos e excesso de trâmites. Todos esses fatores acabam por desmotivar os agricultores para adentrarem nesse mercado institucional.

Neste sentido, o estudo também possibilitou levantar algumas propostas para o aprimoramento do Programa. As principais proposições apontam para a criação de mecanismos que visam ampliar o envolvimento das prefeituras com o Programa. Um passo nessa direção seria mudar a lógica do incentivo oferecido pelas prefeituras aos agricultores. Por exemplo, em vez das administrações municipais subsidiarem serviços de máquinas e oferta de insumos (sementes e adubo), que são as ações mais convencionais, poderia ser ampliada a ATER para os produtores. Considerando os instrumentos de política, uma das formas seria criar incentivos a exemplo dos recursos do Fundo da Educação Básica - FUNDEB, em que quanto maior é o empenho dos municípios maior é o valor recebido por aluno.

Demais proposições estão relacionadas à ampliação do valor disponibilizado por aluno pelo FNDE, tendo em vista que uma alimentação mais saudável gera impactos não apenas sobre o desempenho escolar, mas também nos índices relacionados à saúde, sendo, portanto, uma questão de saúde pública. Dado o papel destacado das cooperativas da AF, estas também poderiam ser alvo de ações, como, por exemplo, o subsídio de ações de ATER para a AF.

Considerando que a pesquisa avaliou apenas um dos atores envolvidos no PNAE, que são as prefeituras, há limitações naturais em nosso trabalho. E, nesse sentido, a comparação dos resultados com outros estudos, a ampliação do número de municípios a serem considerados na amostra e a pesquisa junto aos demais atores do PNAE - principalmente cooperativas e agricultores familiares - são os caminhos básicos para melhorar o escopo da pesquisa.

Apesar dessas limitações, o estudo traz importantes elementos sobre a governança da política e seus resultados podem ser utilizados como insumo para o aprimoramento do PNAE. Sendo assim, a continuação de estudos e a socialização dos resultados junto aos atores do Programa são os próximos passos a serem seguidos.

\section{REFERÊNCIAS}


BACCARIN, J. G. et al. Alimentação escolar e agricultura familiar: alcance e dificuldades para implantação do artigo 14 da lei 11.947/2009 no estado de São Paulo. In: $49^{\circ}$ CONGRESSO DA SOBER, Belo Horizonte, 2011.

BELIK,W. et al. O programa nacional de alimentação escolar como instrumento de desenvolvimento local. In: $49^{\circ}$ CONGRESSO DA SOBER, Belo Horizonte, 2011. Disponível em: <http://www.sober.org.br/palestra/12/070073.pdf >. Acesso em: 01ag02015.

BHARGAVA, A. Food, economics and health. New York: Oxford, 2008.

BRASIL, Lei $\mathbf{N}^{\circ} \mathbf{1 1 . 9 4 7}$, de 16 de junho de 2009, Dispõe sobre o atendimento da alimentação escolar e do Programa Dinheiro Direto na Escola aos alunos da educação básica. Disponível em: <http://www.planalto.gov.br/ccivil_03/_Ato20072010/2009/Lei/L11947.htm> . 2009a Acesso em Junho 2014

BRASIL, Resolução/CD/FNDEn ${ }^{\circ}$ 26, de 17 de junho de 2013, dispõe sobre o atendimento da alimentação escolar aos alunos da educação básica no âmbito do Programa Nacional de Alimentação Escolar (PNAE).

BRASIL, Resolução n ${ }^{\circ}$ 4, de 02 de abril de 2015, Altera a redação dos artigos 25 a 32 da Resolução/CD/FNDE n²6, de 17 de junho de 2013, no âmbito do Programa Nacional de Alimentação Escolar (PNAE).

BUENO, N. P. A lógica da ação coletiva, instituições e crescimento econômico: uma resenha temática sobre a Nova Economia Institucional. Economia, v.5, n.2, p.361420, jul-dez/2004.

CHANG, H.J. Rethinking public policy in agriculture: lessons from distant and recent history. Policy Assistance Series, n.7, Rome: FAO, 2009.

CONSTANTY, H. F. P. H. Contribuições do PNAE na sustentabilidade dos agricultores familiares: o caso do município de Marechal Cândido Rondon-PR. Dissertação apresentada ao Programa de Pós-Graduação em Desenvolvimento Rural Sustentável - Universidade Estadual do Oeste do Paraná. Marechal Cândido Rondon-PR, 2014.

CONTERATO, M. A. et al. Mercados e agricultura familiar: interfaces, conexões e conflitos. Série Difusão IEPE/UFRGS, Porto Alegre: Ed. Via Sapiens, 2013.

COSTA et al. As cooperativas de agricultura familiar e o mercado de compras governamentais em Minas Gerais. Revista de Economia e Sociologia Rural, v. 53, n. 1, p. 109-126, jan-mar/2015.

CRUZ NETO, O.; MOREIRA, M. R.; SUCENA, L. F. M. Grupos focais e pesquisa social qualitativa: o debate orientado como técnica de investigação. In: $13^{\circ}$ Encontro da Associação Brasileira de Estudos Populacionais (ABEP), Ouro Preto, 2002. 
Disponível em: www.dppg.cefetmg.br/mtp/Tecnicade GruposFocaisdoc. Acesso em: 15jul2015.

GRISA, C.; SCHNEIDER, S. Três gerações de políticas públicas para a agricultura familiar e formas de interação entre sociedade e Estado no Brasil. In: GRISA, C.; SCHNEIDER, S. (Orgs). Políticas públicas de desenvolvimento rural no Brasil. Porto Alegre-RS: Ed. UFRGS, 2015, p. 19-50.

GRISA, C.; PORTO, S.I. Dez anos de PAA: as contribuições e os desafios para o desenvolvimento rural. In: GRISA, C.; SCHNEIDER, S. (Orgs). Políticas públicas de desenvolvimento rural no Brasil. Porto Alegre-RS: Ed. UFRGS, 2015, p. 155-180.

HEBINCK, P. et al. The construction of new, nested markets and the role of rural development policies: some introductory notes. In: HEBINCK, P. et al. (ed.). Rural development and the construction of new markets. New York: Routledge, 2015.

HODGSON, G. M. Reclaiming habit for institutional economics. Journal of Economic Psychology, v. 25, p. 651-660, 2004.

KAGEYAMA, A. Desenvolvimento rural: conceito e um exemplo de medida. In: XLII Congresso da SOBER. Anais, Cuiabá-MT, 2004. Disponível em:

http://www.sober.org.br/palestra/12/12O506.pdf. Acesso em: 20jan2016.

MALUF, R. S. J. Segurança alimentar e nutricional. Petropolis: Vozes, 2007.

MILONE, P.; VENTURA, F. The visible hand in building new markets for rural economies. In: HEBINCK, P. et al. (ed.). Rural development and the construction of new markets. New York: Routledge, 2015.

MIOR, L. C. Agricultores familiares, agroindústrias e redes de desenvolvimento rural. Chapecó-SC: Argos, 2005.

MONEGO, E. T. et al. Produção e potencial agrícolas de alimentos destinados a alimentação escolar em Goiás e no Distrito Federal, na Região Centro-Oeste do Brasil. Revista de Nutrição, Campinas, v. 2, n. 26, p. 233-241, 2013.

NAVARRO, Z. Desenvolvimento rural no Brasil: os limites do passado e os caminhos do futuro. Estudos Avançados, v. 15, n. 43, 2001.

NIEDERLE, P. A. et al. Agricultura familiar, desenvolvimento rural e um modelo de mercados múltiplos. In: DOULA, S. et al. (Org.) A agricultura familiar em face das transformações na dinâmica recente dos mercados. 1ed. Viçosa: Suprema, 2014, p. 43-68.

NIEDERLE,P.; GRISA, C. Diversificación de los medios de vida y acceso a actores y activos: un abordaje sobre la dinámica de desarrollo local de la agricultura familiar. Cuadernos de Desarrollo Rural, v.5, n. 61, p. 41-69, 2008. 
PLOEG, J. D. V. D. Newly emerging, nested markets: a theoretical introduction. In: HEBINCK, P. et al. (ed.). Rural development and the construction of new markets. New York: Routledge, 2015.

PLOEG, J. D. V. D. et al. Rural development: actors and practices. In: MILONE, P. et al. (Ed.) Constructing a new framework for rural development. Emerald Group Publishing Limited, 2015.

RIBEIRO, A.L.P.; et al. Programa Nacional de Alimentação Escolar (PNAE) e a participação da agricultura familiar em municípios do Rio Grande do Sul. Revista Gestão e Desenvolvimento em Contexto, v. 1, n. 1, 2013.

SACCO DOS ANJOS, F.; BECKER, C. Agricultura familiar e mercados institucionais: 0 desenvolvimento como liberdade. Rev. Econ. NE, v. 45, suplemento especial, p. 92101, 2014.

SCHNEIDER, S. Situando o desenvolvimento rural no Brasil: o contexto e as questões em debate. Revista de Economia Politica, v. 30, n. 3, p. 511-531, jul-set/2010.

SECCHI, L. Políticas públicas: conceitos, esquemas de análise, casos práticos. $2^{\mathrm{a}}$ ed. SP: Cengage Learning, 2013.

SILVA, M. G; SILVA, S. P. Para além do acesso: uma análise da relação entre mercados institucionais e empreendimentos de economia solidária no meio rural. Boletim Mercado de Trabalho, IPEA, nov/2011.

TESTA, V. et al. 0 desenvolvimento sustentável do Oeste Catarinense: proposta para discussão. Fpolis-SC: EPAGRI, 1996.

TRICHES, R. M. Repensando o mercado da alimentação escolar: novas institucionalidades para o desenvolvimento rural. In: GRISA, C.; SCHNEIDER, S. (Orgs). Políticas públicas de desenvolvimento rural no Brasil. Porto Alegre-RS: Ed. UFRGS, 2015, p. 181-200.

TRICHES et al. Dificuldades e recursos de superação mobilizados por atores sociais na aquisição de produtos da agricultura familiar para a alimentação escolar nos estados de São Paulo, Paraná, Santa Catarina e Rio Grande do Sul. In: PEREZCASSARINO, J. et. al (Orgs). Abastecimento alimentar: redes alternativas e mercados institucionais. Chapecó-SC: Ed. UFFS, 2018, p. 91-105.

YIN, R. K. Case study research: design and method. Third Edition. Applied Social Research Methods Series, v. 5, 2002.

\section{Darlan Christiano Kroth}


Análise da operacionalização da política de aquisição de alimentos da agricultura familiar por parte dos municípios: o caso do PNAE em três microrregióes do Oeste Catarinense

Universidade Federal da Fronteira Sul/Campus Chapecó - Chapecó - Santa Catarina - Brasil

Valdecir José Zonin

Universidade Federal da Fronteira Sul/ Campus - Erechim - Rio Grande do Sul Brasil

\section{Tomé Coletti}

Universidade Federal da Fronteira Sul/Campus Chapecó - Chapecó - Santa

Catarina - Brasil

\section{Willian Simões}

Universidade Federal da Fronteira Sul/Campus Chapecó - Chapecó - Santa

Catarina - Brasil

\section{Eduardo Von Dentz}

Universidade Federal de Santa Catarina - Florianópolis - Santa Catarina - Brasil

\section{Submetido em: 27/05/2017}

\section{Aprovado em: 27/11/2018}

Como citar: KROTH, Darlan Christiano et al. Análise da operacionalização da política de aquisição de alimentos da agricultura familiar por parte dos municípios: o caso do PNAE em três microrregiões do Oeste Catarinense. Redes, Santa Cruz do Sul, v. 24, n. 1, p. 138-162, jan. 2019. ISSN 19826745. Disponível em: https://doi.org/10.17058/redes.v24i1.9697. 